\title{
The Utilization of Web-Based Instruction in the Information Technology Education (ITE) Programs
}

\author{
Flordeline A. Cadeliña, DTE \\ Mindanao State University-Naawan Campus, \\ Naawan, Misamis Oriental
}

\begin{abstract}
This study analyzed the utilization of web-based instruction and devised a model or framework of quality web-based instruction (WBI) in teaching. It aimed to answer questions that dealt with the use of web applications software and the utilization of the web-based training in the BS in Computer Science, BS in Information Technology and BS in Information System programs in shifting to learning competency outcomes-based education. The study utilized the descriptive research design, specifically, survey, and bivariate correlation techniques to measure the extent of the relationships between the variables. Pearson's Product-Moment Correlation Coefficient was performed for the bivariate correlation analysis and established cut-off points by terciles to classify the studied sample according to the level of instructors' use of web-based instruction. The study revealed that there are three factors influencing the instructors' perception, namely: (a) Administrative Support; (b) Urgency in the use of WBI; and (c) Availability of equipment/facilities. However, it is found out that the instructor's use of WBI is not significantly correlated with their perceived factors relative to administrative support; urgency and availability of equipment/facilities. Based on the findings, a learning model of web-based instruction for Information Technology Education programs is developed.
\end{abstract}

Keywords: web-based learning, WBI in higher education institutions, utilization.

\section{Introduction}

Instructors in all disciplines know that students in their class are unique. Students bring experiences in the classroom that will impact who they are as students. In teaching Information Technology Education (ITE), the curriculum is trying to meet a wide range of methods and techniques when designing computer programming activity and developing software. Instructors who teach these programs deliver instruction by recording and narrating screen casts or creating videos of themselves teaching, or collecting video lessons from trusted internet sites for lectures and computer laboratory activities. Students also in these programs watch the videos or screen casts as many times as they need to perform the hands-on activity that will support computational practice by helping find ideas and coding new program.

The increasing growth and use of the internet provide new opportunities for delivering instruction in the classroom. The internet can be used to provide instructional support from trusted internet sites. Davidson-Shiver, Rasmussen \& Lowenthal (2018) expresses that the use of web offers a wealth of information on various websites. This is also a form of a repository of information to help students to access, retrieve, and understand a lot of application programs that will facilitate mental skills in coding a complex computer program. With this kind of teaching delivery, students can focus on the subject matter using either the Internet or an Intranet. There are many application tools and features of web-based instruction with the use of software programs that allow students to access and use the needed learning materials. Groff (2017), mentioned that personalized learning aims to speed up student learning by tailoring the education environment to what, when, how, and where students learn to address each student's individual needs, skills, and interests. Students will 
take possession of their learning, whereas conjointly developing deep, personal connections with one other, their instructors and classmates. The advantage of exploiting web-based learning is the identical content is delivered to some students and might be accessed with no restrictions of time and place.

In that way, students have enough time, more understanding, and can control the pace and sequence of instructions in learning, which help them in improving their knowledge. Besides, the students' motion from being the product of teaching to the path of learning where they are actively involved in knowledge formation through the chance to participate in and evaluate their education in a personally meaningful manner. Karabulut-Ilgu, Cherrez \& Jahren (2018) explained that webbased instruction allows for a variety of learning styles to reach individual students through the use of different learning modes such as combining video, sounds, and the pictures. For example, the flipped classrooms learning management system that deliberate shift from a teacher-centered schoolroom to a student-centered approach, wherever in-class time is supposed for exploring topics in larger depth and making richer learning opportunities(Karabulut-Ilgu et al., 2017).

The effectiveness of web-based instruction must be appropriately evaluated to gauge the performance of the learners and to assess the efficiency of the application programs. Analyzing the web-based learning yields useful information about the results of instruction and it is in itself a necessary component of proper teaching. Instructors in the ITE programs in HEIs should critique how web-based application tools are being created and should consider the quality of the instructional design. In noting such challenge, the need has been answered based on provisions of the Philippines Republic Act (RA) No. 7722 other known as the "Higher Education Act of 1944". The Commission of Higher Education (CHED), Memorandum Order No. 25, series of 2015 to workout innovativeness and creativity in the development of the curriculum in the offering of Bachelor of Science in Computer Science (BSCS), Bachelor of Science in Information System(BSIS), and Bachelor of Science in Information Technology (BSIT) to shift to outcomes-based approach for all public and private Higher Education Institution (HEIs).

However, applying the use of such instructional materials like web-based instruction is not enough and can never be useful, if and when the one who uses these do not have enough skills in his/her presentation. Presenting instructional materials by someone with inadequate skill in the use of these technologies does not supplement student learning. Therefore, to attain a specific goal in teaching, instructors must have thorough skills and training in making instructional materials such as web-based instruction to gain a productive and effective lecture.

Thus, this study sets out a simple aim which is to assess the instructors' utilization of webbased instruction in the Information Technology Education (ITE) programs of Higher Education Institutions (HEIs). Measures, recommendations and a proposed learning model or framework for quality web-based instruction will be devised to improve the standard and quality of teaching in the teaching-learning process.

\section{Method}

\section{Participants}

The participating schools are all ITE programs of HEIs in Iligan City, Philippines that utilize webbased instruction. These higher education institutions are Mindanao State University-Iligan Institute of Technology (MSU-IIT), Iligan Capitol College (ICC), Iligan Medical Center College (IMCC), St. Michael's College (SMC) and St. Peter's College (SPC). The respondents are the fifty (50) ITE instructors including allied programs namely the Bachelor of Science in Electronics and Communication Engineering (BSECE), Bachelor of Science in Electrical Engineering (BSEE), and Bachelor of Science in Computer Engineering (BS Com E.).

\section{Design}

This study employed descriptive and survey methods of research. Descriptive design allows orderly description based on event and facts as well as on the numbers of times happens. To this, applying this model to the recent study for it digs into the present utilization of web application in the information technology education curriculum and measures the extent of the relationship between the variables. 


\section{Materials}

A questionnaire consisting of sixty-six (66) questions with three (3) parts i.e. 'Factors influencing the usage of Web-based learning', 'Instructors' Use of Web-based learning', and 'Characteristics of Webbased Instruction'.

Part I on Factors influencing the use of Web-based consisted focused on Administrative Support, Urgency, and Availability and Preference. Part II and III questioned how ITE instructors of the Higher Education Institutions (HEIs) use web-based instruction and lastly, the characteristics of web-based instruction regarding availability and perceived ease of use. This survey instrument was contained of Likert-type questions, scaled items, checklists, and closed-ended and open-ended questions.

\section{Procedure}

The total population of higher education institutions' web-based instruction users was taken as respondents. Participants were observed inside the classroom or using the web application or any learning management system. It is further observed on the hardware and software used in the web application for presentation as to the convenient of students and the instructions' in learning.

\section{Results}

Table 1 presents the eight (8) indicators of the instructors' utilization of web-based instruction in the information technology curriculum in the academic environment.

Table 1: Instructors' Utilization of Web-Based Instruction

\begin{tabular}{|l|l|l|l|}
\hline Indicator & Mean & SD & Description \\
\hline $\begin{array}{l}\text { 1. Assign students with programming } \\
\text { tasks that involve retrieving and } \\
\text { analyzing algorithmic complex software } \\
\text { from the Internet. }\end{array}$ & 4.33 & .72 & To a very great extent \\
\hline $\begin{array}{l}\text { 2. Use either web-based teaching tools } \\
\text { or learning management software. }\end{array}$ & 4.37 & .57 & To a very great extent \\
\hline $\begin{array}{l}\text { 3. Use web applications to prepare } \\
\text { lessons. }\end{array}$ & 4.29 & .65 & To a very great extent \\
\hline $\begin{array}{l}\text { 4. Use appropriate web application, } \\
\text { websites to learn to code, and video } \\
\text { tutorials to expand the teaching of } \\
\text { sophisticated software. }\end{array}$ & 4.24 & .60 & To a very great extent \\
\hline $\begin{array}{l}\text { 5. Use web application to support } \\
\text { classroom management tasks such as } \\
\text { taking attendance, recording students' } \\
\text { scores, etc. }\end{array}$ & 3.91 & .67 & To a great extent \\
\hline $\begin{array}{l}\text { 6. Outline and use student-centered } \\
\text { learning materials on the topics using } \\
\text { web application software for teachers } \\
\text { such as Edmodo, Moodle. }\end{array}$ & 4.20 & .58 & To a great extent \\
\hline $\begin{array}{l}\text { 7. Require students to use the internet } \\
\text { for complex computing problems. }\end{array}$ & 4.29 & .65 & To a very great extent \\
\hline $\begin{array}{l}\text { 8. Use the recent software and web- } \\
\text { based innovation software. }\end{array}$ & 4.27 & .53 & To a very great extent \\
\hline $\begin{array}{l}\text { Average } \\
\text { To a very great extent }\end{array}$ \\
\hline
\end{tabular}

The average mean and standard deviation are of 4.24 and .41 respectively. The instructors use the web application to augment traditional instruction in several ways. Kitsantas \& Dabbag 
(2011) confirms in their study that teaching students to become active self-controlled learners may help them gain basic complex personal knowledge and skills that are incredibly crucial of creating, managing, and sustaining a variety of web applications.

Furthermore, Okello-Obura \& Ssekitto (2015) mentioned that the high acceptance of web application had changed the perception of what is and how it should be developed, the preparation to install these new learning principles, but then again, they need to understand. ITE is going to change school education, especially in the way instructors teach and the way our students learn. Moreover, incorporating instructional strategies to engage students can increment learners' level of contentment and at the same time enable students to increment their research skills (Budhai \& Williams, 2016).Unfortunately, recent advances in an academic environment most would argue the weaknesses of such a static approach and may not always be comparable to learning. With this, they are reiterating the CHED Memorandum Order 25, s. 2015 to shift to an outcomes-based approach that the students must be active participants in their education, engaged rather than recumbent. The results show that the respondents use to a very great extent web-based learning or learning management software. This obtained the highest mean score of 4.37, and the students are also assigned to a very great extent. This means that the instructors' utilization of web-based learning can help students to meet their academic needs.

On the other hand, the lowest indicator 'use web applications to support classroom management tasks such as taking attendance, recording students' scores, etc.' obtained a mean score of 3.91 and implied to a great extent. Hence, good teaching provides individual learning experiences within the learning environment by using a mix of media, techniques, and procedures. Learning experiences that will promote interaction allows the students to think about information. There can be remembered and combined with other experiences so that new knowledge bases may be formed. When creating and designing a web-based instruction, it should be flexible and adaptable to ITE students in coding complex computer program. Instructors teaching the ITE curriculums need to examine the learning process and components of a comprehensive computer hands-on exercise and activity design. With this, designing a web-based instruction will make more efficient, effective, and less difficult for students and will help instructors in repeating the discussion or instruction in performing the complex computer program.

According to Allen and Seaman (2013) the number of students taking a minimum of one online courses in the academic environment of higher education a total of 6.7 million. The growth of online enrollments, instructors are being asked to developed and teach online courses. Creating the switch from face-to-face instruction to online have posted rising problems and consideration for instructors. Thormann and Zimmerman (2012) found that the preparation of the curriculum and its implementation are important types of variations between teaching courses online and face-to-face. Some problems that are known express time commitment (Lewis \& Abdul-Hamid, 2006), usage of technology tools and/or learning management systems (De Gagne \&Walters, 2009), implementation of acceptable educational approaches (Brinthaupt, Fisher, Garber, Raffo, \& Woordward, 2011), and adapting to the role of facilitator (Johnson, 2008).

Further, previous studies found students using the Web site to be useful to examine the academic content. Also, it was found out that the availability of the Web site increased pressures on teachers to prepare students for high-stakes testing. Therefore, instructors are more likely to use the resources of classroom instruction. Further, Carr (2008), said that most instructors designed to utilize a method that is compelling, productive, and gratifying.

Liang \& Creasy (2004) shared his perceptions that there are numerous reasons why instructors may select to utilize web-based instruction. He further added that improving student learning, reducing repetitive tasks of teaching; lessen paper stream and managing and giving developed instructional materials. Web-based instruction makes a difference on numerous levels of education in one room with a single instructor. Generally speaking, the web-based instruction is clearly favored in this study; it is worthwhile to note that the teaching effectiveness of an instructor may significantly increase depending on his/her ability to make the most out of the different teaching modes. The instructors' main preoccupation is concerned with using the precise method in the right situation and at the proper time. In other words, instructors should be able to maximize 
his/her efficiency through the application of an appropriate method of teaching such as the utility of web-based instruction and their applications.

\section{Discussion}

Web-based application for ITE programs in instructing and learning are indorsed by the properties and the assets of the Web. There are two equally important aspects of WBI; first, an online curriculum, which includes all the concepts information and resources necessary to complete assigned work; second, an online class management systems (CMS), including resources for online communication and interaction as well as class calendar and assignment schedule. The WBI embraces learning environment and has several advantages over traditional textbook-based instruction. Instructor to customize the curriculum to suit their philosophy of teaching and can be updated at any time.

In particular, the instructors in Information Technology Education (ITE) programs utilize web-based instruction for core and allied courses and having positive experiences. Also, they maximize technology in instructing and progress the quality of conveyance of education. Additionally, instructors' utilization of web-based instruction was to a very great extent, and it is favorable to the respondents.

The instructors in the Information Technology Education (ITE) programs are using webbased instruction in teaching faces the necessity in use of technology in teaching. Thus, this model hopes to provide a framework or structure to help them understand large complex concepts and to break these into separate and manageable units in the development.

The Web-based Instruction Information Technology Education (WBIITE) Model: A Pedagogy, Collaboration, Delivery Quality Instruction (PCDQI) helps to produce quality teaching materials for teaching. The web-based instruction proposed model demonstrate performance outputs as well as behavioral inputs, that narrate to a system or set the standards that required for effective performance at work. The model of this study represents the earth and a tree. The earth is represented as the quality of web-based instruction that serves as the storage that gives life to a tree. Then, the root and trunk signify the pedagogy which is divided into three categories: first, preparation; second, techniques and third, the tools. Thus, the said categories are essential to the use of the instructor in the development of web-based instruction.

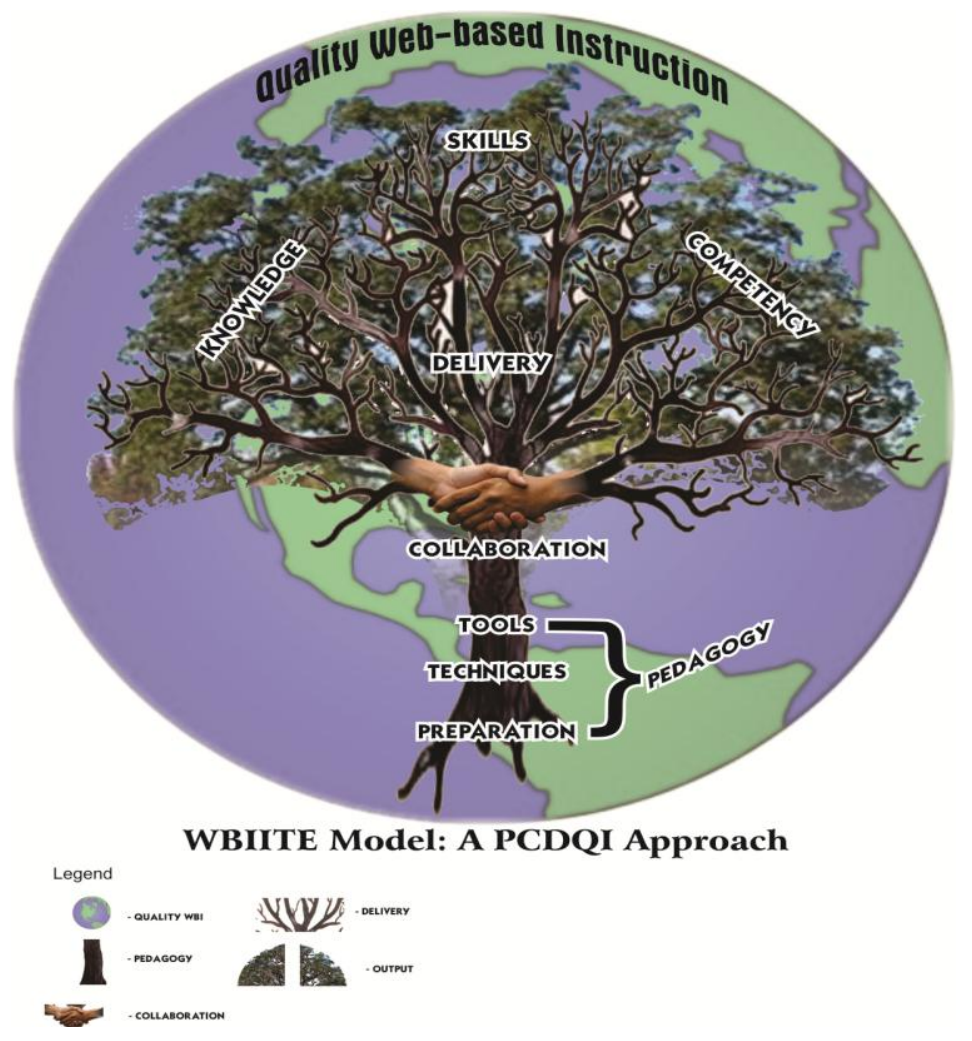

Figure 1: A Learning Model for the ITE Instructors Through Web-based Instruction Using PCDQI Approach 


\section{Conclusion}

There were eight (8) indicators of the instructors' utilization of web-based instruction namely: (1) Assign students with programming tasks that involve retrieving and analyzing algorithmic complex software from the Internet.; (2) Use either web-based teaching tools or learning management software; (3) Use web applications to prepare lessons; (4) Use appropriate web application, websites to learn to code, and video tutorials to expand the teaching of sophisticated; (5) Use web application to support classroom management tasks such as taking attendance, recording students' scores, etc.;(6) Outline and use student-centered learning materials on the topics using web application software for teachers such as Edmodo; (7) Require students to use the internet for complex computing problems; and (8) Use the recent software and web-based innovation software. In general, the study has shown that the instructor using web-based instruction indicates a very great extent. The instructors' in the Information Technology Education (ITE) programs in Iligan City have a positive perception in utilizing instructional technologies to enhance teaching.

\section{References}

Allen, I., \& Seaman, J. (2013). Changing course: Ten years of tracking online education in the United States. Retrieved from http://sloanconsortium.org/publications/survey/changing_course_2012.

Budhai, S. S., \& Williams, M. (2016). Teaching presence in online courses: Practical applications, cofacilitation, and technology integration. Journal of Effective Teaching, 16(3), 76-84.

Brinthaupt, T., Fisher, L., Gardner, J., Raffo, D., \& Woodward, J. (2011). What the best online teachers do. Journal of Online Learning and Teacbing, 7(4), 515-524.

Carr, J. (2008). Approaches to Teaching \& Learning, Irish National Teachers' Organisation Consultative Conference on Education 2007, Dublin. Retrieved from https://www.into.ie/ROI/Publications/ApproachesTeachingandLearning.pdf.

Davidson-Shivers, G. V., Rasmussen, K. L., Lowenthal, P. R. (2018). Web-based learning: Design, implementation, and evaluation (2nd ed.). New York, NY: Springer.

De Gagne, J. C., \& Walters, K. (2009). Online teaching experience: A qualitative meta-synthesis (QMS). Journal of Online Learning and Teaching, 5(4), 577-589.

Groff, J. S. (2017). Personalized Leaming: The State of the Field \& Future Directions. Center for Curriculum Redesign. Retrieved from https://curriculumredesign.org/wpcontent/uploads/PersonalizedLearning_CCR_May2017.pdf.

Hamdan, N., McKnight, P., McKnight, K., \& Arfstrom, K. M. (2013). A Review of Flipped Learning. Retrieved from http://www.flippedlearning.org/review.

Karabulut-Ilgu, A., Cherrez, N., Jahren, C. (2018). A System Review of Research on the Flipped Learning Method in Engineering Education. British Journal of Educational Technology, 49(3), 398-411. doi:10.1111/bjet.12548.

Kitsantas, A. \& Dabbagh, N. (2011). The Role of Web 2.0 Technologies in Self-Regulated Learning. New Directions for Teaching and Learning, 126, 99-106.

Liang, X. \& Kim C. (2004). Classroom assessment in web-based instructional environment: instructors' experience. Practical Assessment, Research \& Evaluation, 9(7).

Lewis, C., \& Abdul-Hamid, H. (2006). Implementing effective online teaching practices: Voices of exemplary faculty. Innovative Higher Education, 31(2), 83-98. doi: 10.1007/s10755-006-9010-z.

Okello-Obura, C., \& Ssekitto, F. (2015). Web 2.0 Technologies Application in Teaching and Learning by Makerene University Academic Staff. Library Pbilosophy and Practice (e-journal), 1248, 1-23.

Sterling, S. (2016). A commentary on education and sustainable development goals. Journal of Education for Sustainable Development, 10(2), 208-213.

Thormann, J., \& Zimmerman, I. K. (2012). The complete step-by-step guide to designing and teacbing online courses. New York, NY: Teachers College Press. 